\title{
The Orthopedic Residency Program at Hamad Medical Corporation During COVID-19 Crisis: an Evolving Educational Strategy
}

\author{
Motasem Salameh $^{1} \cdot$ Abduljabbar Alhammoud $^{1} \cdot$ Mohammad Al Ateeq Al Dosari ${ }^{1} \cdot$ Ghalib Ahmed AlHaneedi $^{1,2,3}$ (D)
}

Accepted: 6 October 2020 / Published online: 14 October 2020

(C) International Association of Medical Science Educators 2020

\begin{abstract}
The COVID-19 pandemic has changed the strategies of most of the teaching hospitals worldwide, affecting the educational process in residency programs. The System Wide Incident Command Committee in the state of Qatar has set the country's medical response to the crisis. In line with command committee directives, the orthopedic surgery residency program planned an educational strategy keeping the trainees' wellbeing and education a priority and taking advantage of the pandemic as a tool of personal and professional growth.
\end{abstract}

Keywords COVID-19 $\cdot$ Education $\cdot$ Residency $\cdot$ Orthopedic

\section{Introduction}

COVID-19 has rapidly become a worldwide public health threat, endangering the health and wellbeing of all people, especially vulnerable populations [1-3]. Controlling the spread of COVID-19 has become the essential focus of almost all countries worldwide, with unprecedented international collaboration and rapid dissemination of emerging scientific evidence [1-3]. During natural disasters and emergency plans, residents' wellbeing and education were the top priority of the residency programs and institutions. Hence, greater flexibility to accommodate resident training needs was required [4]. In a recent report from Wuhan, 19 orthopedic surgeons were COVID-19 positive with an incidence ranging from 1.5 to $20 \%$ in some hospitals, with the highest exposure risk in general wards [5].

The state of Qatar, through Hamad Medical Corporation (HMC), has developed the institution's COVID-19 command center called "System Wide Incident Command

Ghalib Ahmed AlHaneedi

gahmed@hamad.qa; ghaliboudah@yahoo.com

1 Orthopedic Surgery Department, Hamad General Hospital, Hamad Medical Corporation, Doha, Qatar

2 Orthopedic Residency Training Program, Weil Cornell Medical College, Ar-Rayyan, Qatar

3 Hamad Medical Corporation, PO Box 3050, Doha, Qatar
Committee (SWICC)" to provide up to date information about the COVID-19 status and manage the crisis in the country. In line with that, the department of orthopedic surgery, an accredited residency program by the Accreditation Council for Graduate Medical EducationInternational (ACGME-I), at HMC started planning a strategy to deal with the COVID-19 crisis. Our main priority was the wellbeing of our residents and faculty, the continuation of education and training, and taking opportunity to learn from each other implementing the ACGME-I core competencies.

\section{SWICC Actions Affecting Surgical Departments}

Several SWICC plans to fight the COVID-19 pandemic had a considerable effect on the surgical departments, including and not limited to the following: all elective operating lists were postponed, and the orthopedic theatres were kept only for acute trauma and musculoskeletal oncology cases. Tele-clinic outpatient service was initiated, and only urgent cases were seen in the clinic as directed by the attendings. All departmental meetings, morning reports, and educational activities were suspended. Furthermore, instructions to keep a list of the available trainees and faculty standby in order to be mobilized to quarantine camps and COVID-19 isolation facilities, or to cover other services as needed. 


\section{Residency Program Modifications}

In line with the SWICC action plan, a task force including the head of the department, residency program director, associate program directors, and the chief resident was formed immediately, and several strategies were implemented in the orthopedic surgery department and residency program to ensure the continuation of the educational process. These strategies were guided by the 6 core competencies that have been set by the ACGME-I to ensure a well-structured training program: patient care, knowledge, system-based practice, professionalism, practice-based learning, and communication skills.

\section{Clinical Rotations}

Clinical and surgical exposure is the core of orthopedics training; the postponement of the elective procedures and non-essential outpatient visits resulted in a decline in clinical exposure.

To adapt with these changes and to comply with the ACGME-I requirement, modifications of the residents' rotation schedule were implemented. The residents were divided into four rotating groups, group A: orthopedic trauma rotation, group B: research rotation, group C: other elective subspecialties (musculoskeletal oncology and pediatric orthopedics), and group D: COVID-19 coverage. Furthermore, a specialized training for acute care triage and screening for suspected COVID-19 and the use of personal protection equipment (PPE) were given to all residents.

The orthopedic trauma group (group A) was covering the trauma and acute orthopedic consultations in emergency, attended the orthopedic trauma daily operating theatre, and facilitated inpatient and outpatient post-operative care. Residents attended patients in the emergency department with full PPE and complied with the evolving and daily updated peri-operative guidelines of COVID-19 screening and testing for surgical cases.

Due to the decreased clinical exposure, many PGY2 and PGY4 residents were mobilized to their research rotation (group B). The residents were working on their audits, research proposals, and manuscript from home under the guidance of their assigned mentors. Weekly progress updates were discussed with the mentors on virtual settings. This allowed the trainees to complete their ACGME-I requirements and spared the future blocks for clinical rotations when the COVID-19 curbs are lifted.

Group $\mathrm{C}$ were rotating with the musculoskeletal oncology and the pediatric orthopedic teams; they continued their training through supervised real and phone consultations for new and follow-up patients. This gave a good time for case discussions and review of imaging studies with the attending faculty before the virtual counseling. Furthermore, they attended operating theatres for musculoskeletal oncology and pediatric trauma cases that were not stopped during the pandemic.

\section{Didactic Educational Activity}

The continuation of educational activity is an essential aspect of any residency program. Residents' grand round, journal club, and series of orthopedics didactic lectures were scheduled and conducted as an online interactive webinar on Microsoft Teams application using institutional accounts for all residents and faculty. At the scheduled time, residents at all locations were linked to attend and participate in the discussions supervised by faculty. Furthermore, the department organized a monthly webinar in collaboration with international faculty from the USA, Europe, and India to discuss high yield topics.

Developing virtual study groups for each PGY level with the supervision of assigned faculty or senior resident to review daily topics and relevant literature was another tool to keep the residents engaged and updated. Several educational material and videos were posted in these groups on regular basis.

The feedback from trainees and faculty was very positive; most of them enjoyed the new learning experience and expressed their welling to continue with online education even after the crises is resolved.

The decrease in work load and service demands gave the residents more time to explore the newly made available educational modalities in response to COVID-19, as they were able to attend several online courses and webinars from all over the world.

\section{Personal and Professional Growth}

Working during crisis was a good opportunity for our trainees for development on both personal and professional levels. For the residents redeployed to COVID-19 facilities, they developed new skills and gained knowledge in new areas other than orthopedic surgery. Furthermore, working in field hospitals and quarantine camps was a new experience for most of the trainees, and a chance to implement ACGME-I competencies. On the other hand, the evolving peri-operative protocols and the daily changes on COVID-19 screening and testing guidelines were a true challenge to the residents remaining in the orthopedic department.

On the personal level, during the lockdown, trainees had more time to reflect on themselves exploring new hobbies and innovating ways to cope with the new situation, and most importantly more time to connect with family and friends. 


\section{Residents' Wellbeing}

At the beginning of the crisis, a program trainees' wellbeing questionnaire was sent to all residents in our program to identify residents at high risk for COVID-19 infection or complications. The orthopedic residents were informed ahead of time that they might serve at different facilities dealing with suspected or confirmed COVID-19 patients. A training course was conducted for residents on the standby list focusing on protection measures and basic respiratory and intensive care. COVID-19 mental health helpline for medical professionals was launched to address mental health concerns resulting from the crisis.

On the other hand, HMC continued to fund residents' salaries to ensure normal life and avoid unnecessary stress. Furthermore, the Qatar Council for Healthcare Practitioners (QCHP) licensing boards across the country granted a temporary emergency extension of licenses to all residents, faculty, and other health professionals to facilitate the workflow and patient care.

\section{Orthopedic Program Learning Opportunities}

1. Working with trainees and faculties from another residency program provides a unique opportunity to our residents to be exposed to another style of medical education.

2. Working for a time in crisis will be a chance to implement ACGME-I competencies especially professionalism, communication and interpersonal skills, and systembased learning, and considered as a learning opportunity for personal and professional growth

3. Using modern technology, residents have the opportunity to evolve their clinical skills in the ability to take care of the patient through virtual consultation, and develop their presentation skills using web-based learning.

4. Most of the orthopedic physicians demonstrate an exceptional commitment to supervise the resident acute and virtual orthopedic care and virtual online educational activities, hence, keeping our program fresh and alive.

\section{Recommendations}

Based on the orthopedic program strategy, the following suggestions during crisis are recommended:

1. Funding residents' salaries and reorganization of residents' work and wellbeing should be a priority.

2. Establishment of alternative modes of communications. All programs should consider establishing a directory of e-mail addresses of all faculty and residents along with telephone numbers that can be accessed by the head of department, program director, and program coordinator.

3. Communication with residents and faculty on a frequent, regular basis to address their concerns, sharing updates on the residency program and the ACGME-I announcements.

4. Continuation of the program educational activity through distance web-based tools reaching residents in different locations.

5. Management of stress and fatigue of residents and faculty through regular communications and online meetings.

6. Post-crisis planning to restore the regular training and educational activities, and to assess and solve any impact on the training program in collaboration with the ACGME-I.

\section{Conclusion}

Greater flexibility of residency training program is required to accommodate the current challenges with the COVID-19 pandemic, ensuring the trainees wellbeing, maximizing learning opportunities with the new clinical exposure and the continuation of educational and scholar activities, hence a chance for personal and professional growth.

Acknowledgments We acknowledge the contribution of Dr. Shamsi Hameed, Dr. Hasan Abu Hejleh, Dr. Basim Ameen, Dr. Aissam Elmhiregh, and Dr. Safa Abulhail.

Authors' Contribution MS: manuscript draft writing, final manuscript revision

AA: manuscript draft writing

GA: strategy planning, manuscript draft writing

MA: strategy planning, final manuscript revision

Data Availability Not applicable

\section{Compliance with Ethical Standards}

Conflict of Interest The authors declare that they have no conflict of interest.

Code Availability Not applicable

\section{References}

1. Mao R, Liang J, Shen J, Ghosh S, Zhu LR, Yang H, et al. Implications of COVID-19 for patients with pre-existing digestive diseases. Lancet Gastroenterol Hepatol. 2020;5:425-7. https://doi. org/10.1016/S2468-1253(20)30076-5.

2. Tsai J, Wilson M. COVID-19: a potential public health problem for homeless populations. Lancet Public Heal. 2020;5:e186-7. https:// doi.org/10.1016/S2468-2667(20)30053-0. 
3. Vannabouathong C, Devji T, Ekhtiari S, Chang Y, Phillips SA, Zhu M, et al. Novel coronavirus COVID-19. J Bone Jt Surg 2020;Latest Art:1. https://doi.org/10.2106/jbjs.20.00396.

4. Espana-Schmidt C, Ong EC, Frishman W, Bergasa NV, Chaudhari $\mathrm{S}$. Medical residency training and hospital care during and after a natural disaster: hurricane sandy and its effects. Am J Med. 2013;126:944-5. https://doi.org/10.1016/j.amjmed.2013.03.031.
5. Guo X, Wang J, Hu D, Wu L. The Orthopaedic Forum Survey of COVID-19 Disease Among Orthopaedic Surgeons in Wuhan, People's Republic of China. JBJS 2020:1-15. https://doi.org/10. 2106/JBJS.20.00417.

Publisher's Note Springer Nature remains neutral with regard to jurisdictional claims in published maps and institutional affiliations. 